\title{
Von Zürich aus an die Westfront
}

Während des Ersten Weltkriegs, an dem Sauerbruch bis 1915 als Beratender Chirurg des 15. deutschen Armeekorps kriegsfreiwillig und beurlaubt von seinen Zürcher Dienstverpflichtungen in Straßburger Lazaretten teilnahm, entwickelten sich allerdings auch bereits Persönlichkeitszüge, die zur Versachlichung seiner durch die späteren Lebenserinnerungen „Das war mein Leben“ und den gleichnamigen Spielfilm verklärten Biographie drängen. So erregten in Zürich nicht nur der extrem autoritäre Führungsstil des Chirurgen und sein eruptives, vollkommen unkalkulierbares Auftreten bei medizinischen Examina Aufsehen und Widerwillen. Hinzu kamen hartnäckige Gerüchte über unmäßige Honorarforderungen, die sich zwar bereits 1912/1913 als haltlos herausgestellt hatten, aber gleichwohl den Argwohn der Eidgenossen weckten und sich bis in die frühen 1930er Jahre hielten (vgl. Mörgeli, in: Schweiz. Rundschau Med. (PRAXIS) 82 (1993) Nr. 15, S. 451 ff.). Der Umstand gar, daß Sauerbruch in der neutralen Schweiz seinen amtsältesten Assistenten, Dr. Heinrich Freysz (1884-1963), wegen dessen frankophiler Gesinnung Anfang 1915 kurzerhand entließ und durch die Ausfuhr chirurgischer Instrumente nach Deutschland bereits Ende 1914 die äußere Neutralitätspolitik des nach Innen durch den Weltkrieg gespaltenen Alpenstaates in Misskredit gebracht hatte, provozierte einen Skandal, der das Kantonsparlament und die internationale Presse über einige Monate mit Konfliktstoff belieferte (vgl. Mörgeli, in: Schweizerische Rundschau für Medizin (PRAXIS) 77 (1988), S. 23 ff.).

W. U. Eckart, Ferdinand Sauerbruch - Meisterchirurg im politischen Sturm, essentials, DOI 10.1007/978-3-658-12547-9_4 